\title{
An international randomized study of a home- based self-management program for severe COPD: the COMET
}

This article was published in the following Dove Press journal:

International Journal of COPD

28 June 2016

Number of times this article has been viewed

\author{
Jean Bourbeau' \\ Pere Casan ${ }^{2}$ \\ Silvia Tognella ${ }^{3}$ \\ Peter Haidl ${ }^{4}$ \\ Joëlle B Texereau ${ }^{5,6}$ \\ Romain Kessler ${ }^{7}$ \\ On behalf of the COMET \\ investigators
}

'Respiratory Epidemiology and Clinical Research Unit, Research Institute of the McGill University Health Centre, McGill University, Montreal, QC, Canada; ${ }^{2}$ Hospital Universitario Central de Asturias, Facultad de Medicina, Oviedo, Spain; ${ }^{3}$ Lung Department, Ospedale Orlandi, Bussolengo VR, Italy; ${ }^{4}$ Krankenhaus Kloster Grafschaft, Schmallenberg, Germany; ${ }^{5}$ Air Liquide Healthcare, Medical Research and Development, Jouy-en-Josas, ${ }^{6}$ Assistance Publique-Hôpitaux de Paris, Service de Physiologie Clinique, Hôpital Cochin, Paris, ${ }^{7}$ Department of Pulmonary Medicine, Translational Medicine Federation of Strasbourg, University Hospital of Strasbourg, Strasbourg, France
Correspondence: Jean Bourbeau Center for Innovative Medicine, McGill University Health Centre, I00I Decarie Blvd., Room C04737I.5, Montreal, QC, Canada H4A 3JI

Email jean.bourbeau@mcgill.ca
Introduction: Most hospitalizations and costs related to COPD are due to exacerbations and insufficient disease management. The COPD patient Management European Trial (COMET) is investigating a home-based multicomponent COPD self-management program designed to reduce exacerbations and hospital admissions.

Design: Multicenter parallel randomized controlled, open-label superiority trial.

Setting: Thirty-three hospitals in four European countries.

Participants: A total of 345 patients with Global initiative for chronic Obstructive Lung Disease III/IV COPD

Intervention: The program includes extensive patient coaching by health care professionals to improve self-management (eg, develop skills to better manage their disease), an e-health platform for reporting frequent health status updates, rapid intervention when necessary, and oxygen therapy monitoring. Comparator is the usual management as per the center's routine practice.

Main outcome measures: Yearly number of hospital days for acute care, exacerbation number, quality of life, deaths, and costs.

Keywords: COPD, disease management, exacerbations, hospitalization, home care, clinical trial

\section{Introduction}

Chronic obstructive pulmonary disease (COPD) is a treatable lung disease. In addition to chronic symptoms, patients also suffer from acute worsening episodes (eg, exacerbations) that are common causes of hospitalizations and can be lifethreatening. Since severe COPD is more difficult to manage and patients often have multiple morbidities, both associated with higher health care costs due to frequent hospitalizations, ${ }^{1}$ treatment should emphasize disease self-management in order to optimize outcomes. The premise is that if individuals receive effective self-management, they can be empowered to adopt the behavior needed to cope with their disease on a day-to-day basis and many of the poor outcomes related to chronic diseases can be averted. ${ }^{2}$

Many patients have modifiable risk factors and stand to benefit from proactive intervention; but with the diversity of past investigational studies, an ideal management strategy has yet to be identified. Clear principles have emerged however, and self-management programs have been shown to improve patient health status and to reduce health care reliance, burdens, and costs. Programs that combine three important elements of self-management (education, behavioral changes, and motivation) with 
advanced and timely access to health care have been most effective in improving patient outcome and limiting health care use. ${ }^{3}$ The challenge is that disease management strategies with self-management education need to be carefully targeted to the disease severity and comorbidities involved, and to patient's personal goals to achieve success.

The main objective of the COPD patient Management European Trial (COMET) is to evaluate a multicomponent home-based COPD self-management program compared to usual care on unscheduled all-causes hospital days over 1-year follow-up in severe COPD patients from four European countries. It is hypothesized that the COMET program will help patients with severe COPD learn and adopt the behaviors needed to cope with their disease and consequently this will result in a reduction of hospitalizations. The key interventions of the COMET program involve patient self-management education and coaching by health care professionals, eg, case managers (CMs), to promote self-efficacy, adopt sustainable self-management skills and behaviors; close patient monitoring for early detection of symptom worsening; and health care coordination to reduce treatment delays and improve chronic disease management. Since a number of severe COPD patients have chronic hypoxemia and receive long-term oxygen therapy, the COMET program also includes monitoring of compliance to home oxygen using a novel in-line medical device (NOWOX ${ }^{\circledR}$; Air Liquide Sante International, Paris, France). Indeed, compliance rates to home oxygen could be improved; only $45 \%$ of patients use oxygen for more than the recommended 15 hours/day ${ }^{4}$ and many patients are reluctant to use oxygen outside their home.

\section{Methods}

\section{Study design}

The study is a multicenter, randomized, open, parallel-group trial conducted at 33 centers in four European countries (France, Germany, Italy, and Spain) with a target enrollment of 153 patients assessable for the primary end point analysis in each group (ClinicalTrials.gov identifier: NCT01241526). The trial was approved by the local or national ethics committees and competent authority per country for each investigational center where applicable. The protocol was also submitted to data protection agencies in France: CCTIRS (Comité Consultatif sur le Traitement de l'Information en matière de Recherche dans le domaine de la Santé) and CNIL (Commission Nationale de l'Informatique et des Libertés). The study was conducted according to the current International Council for Harmonisation (ICH) Good Clinical Practice (GCP) guidelines, the Declaration of Helsinki (2008) and the European Directive 2001/20/ EC. All patients provided written informed consent. To be included, COPD patients must have a post-bronchodilator forced expiratory volume in 1 second $<60 \%$, a smoking history of $\geq 10$ pack-years, and at least one moderate (ie, requiring treatment with systemic corticosteroids and/or antibiotics) to severe (ie, requiring hospitalization) exacerbation in the prior 12 months. Exclusion criteria are a probability of survival $<6$ months, be uninsured, or permanently living in a nursing home. Patients are stratified by smoking status (current or former), respiratory assistance need (home oxygen therapy or mechanical ventilation), and center, and then randomized 1:1 into the intervention or comparison group (Figure 1).

Each patient is assessed for respiratory and global health status during a 3- to 5-week run-in period and is then followed-up for a maximum of 24 months. During follow-up, patients are seen every 3 months by the hospital physician and have telephone contacts between visits with the study site to collect health care use within the previous 6 weeks.

\section{COPD self-management program and usual care}

Patients allocated to the intervention group receive selfmanagement education from a $\mathrm{CM}$ at four individual home sessions during the run-in period, and from monthly group or telephone individual sessions during the follow-up period. The investigational home-based COPD self-management program was translated in four languages and adapted from the "Living Well with COPD" program developed at the Montreal Chest Institute, McGill University Health Centre, Montréal, Canada (http://www.livingwellwithcopd.com). ${ }^{5}$ Patients report their symptoms via a telephone-based questionnaire (Supplementary material) at least once per week and each day they feel their clinical status is impaired. Their responses to the questionnaire are automatically transmitted to an electronic health data system (e-health platform) that generates a clinical score indicating a status of well-being, worsening, or alarm. A worsening or alarm status triggers standardized interventions: patients perform self-measurements of pulse oximetry, spirometry, and body temperature, and receive a confirmatory/ supportive phone call from the $\mathrm{CM}$ to put into practice their personalized written action plan (predetermined by the $\mathrm{CM}$ and the hospital physician). Only alarm status is transmitted to the hospital physician for same-day medical assessment and management.

Patients allocated to the comparison group, ie, usual care, receive standard COPD management, as routinely implemented at each investigational center, which varies by center and by country. Routine educational practice data (personnel, topics, duration, etc) are collected for each site at the beginning and end of patient inclusion. 


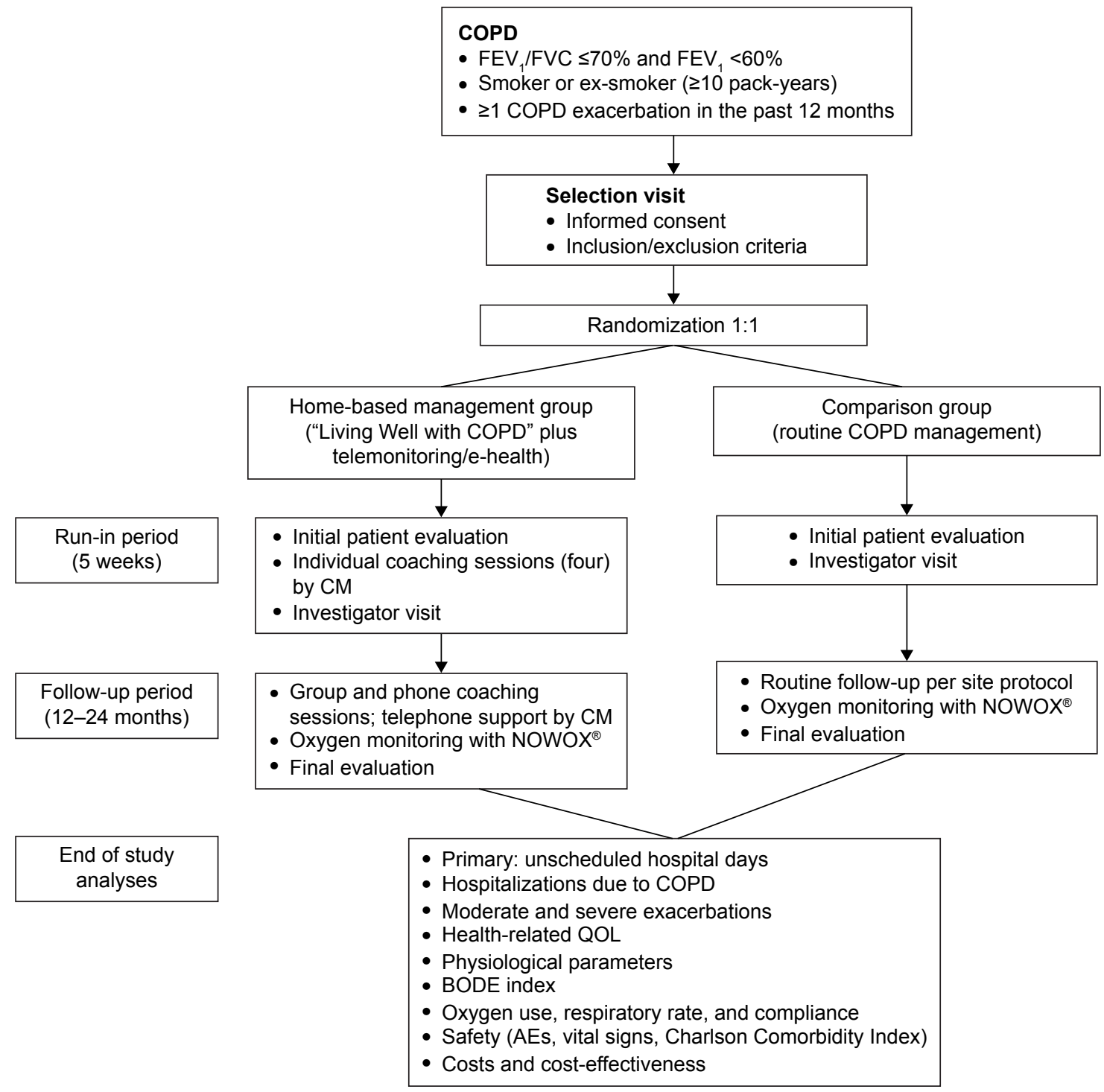

Figure I Design of the COMET study.

Notes: COPD patients are randomized I:I into a home-based management group and a comparison group. Following patient education, the home-based management group provides proactive health status updates weekly or in cases of symptom worsening. Patients reporting worsening or alarm status receive a telephone call by a CM and confirmed cases of alarm status are referred to the investigator for same-day medical assessment and management. Outcomes will be analyzed after all patients have completed their follow-up period of 2 years (maximum) and the study is complete.

Abbreviations: CM, case manager; $\mathrm{FEV}_{1}$, forced expiratory volume in I second; FVC, forced vital capacity; QOL, quality of life; BODE, body mass index, airflow obstruction, dyspnea, and exercise capacity; AE, adverse events; COMET, COPD patient Management European Trial.

In addition, all patients on oxygen therapy are monitored with a NOWOX ${ }^{\circledR}$, which is a wearable device that records time of oxygen use and respiration rate. To allow unbiased analysis of oxygen therapy compliance, $\mathrm{NOWOX}^{\circledR}$ data are retrieved at the end of each patient's participation and are not available to the health care professionals during the study.

\section{Self-management program quality assurance}

Beyond the standardization of the self-management program "Living Well with COPD" and its delivery, program quality is assured by several study features. The expertise required of the CMs is specifically defined as having experience in caring for home-based chronic patients with respiratory condition. CMs undergo a standardized initial 4-day training with specific focus on motivational communication and have continuous access to "reference guides" describing the objectives, interventions, suggested questions, expected results, and available resources. Continuous education and feedback are achieved through monthly telephone contacts between the CMs and a pneumologist from the COMET study coordination center in each country. These contacts are scheduled throughout the entire study period to discuss and address specific issues, to share experiences, and to make 
adjustment when needed. Furthermore, regular CM trainings were implemented at each country level during the study for the new participants and for program refreshing.

\section{Study outcomes}

The primary efficacy outcome is the number of unscheduled all-causes hospital days normalized to 1 year of follow-up for each randomized patient. Hospitalization stays considered are those $>24$ hours, in any acute care ward and in a nursing facility if patients are discharged directly from acute ward to nursing facility. Hospital reports are blindly reviewed and adjudicated by an independent Endpoint Validation Committee for hospitalization criteria, main reason for admission, and cause of prolongation for stays $>30$ days.

Secondary outcome measures include hospital days due to COPD exacerbations; moderate-to-severe COPD exacerbations; all-causes and COPD-related health care service use; deaths; anxiety and depression levels using the Hospital Anxiety and Depression Scale; and health status using the St George Respiratory Questionnaire and the 15D healthrelated quality of life questionnaire. Other measurements included spirometry, echocardiography, 6 minutes walking test, and the body mass index, airflow obstruction, dyspnea, and exercise capacity index; compliance to oxygen therapy, and respiratory rate.

Cost-effectiveness (ie, vs medical outcomes) and costutility (ie, vs quality of life) analyses are planned. Only direct costs, evaluated from health care payer perspective, and costs of the intervention, are analyzed.

\section{Discussion}

COMET has been developed on previous experience of the Canadian self-management program "Living Well with COPD" which demonstrated in a landmark randomized clinical trial ${ }^{5}$ significant reductions in acute care hospital admissions for exacerbation of $39.8 \%$ in the intervention group compared with the usual care group $(P=0.01)$, in emergency department visits of $41.0 \%(P=0.02)$, and in unscheduled physician visits of $58.9 \%(P=0.003)$.

It is expected that COMET will add to the original Canadian trial beyond confirming that this multicomponent home-based COPD management program can prevent some severe acute events and hospitalizations. Of importance, COMET is the first study being implemented across culturally diverse countries with distinct health care systems, and different levels of access and availability. It is a pragmatic trial in which the intervention is delivered by home health care provider professionals for patients with advanced COPD and those who need respiratory assistance (home oxygen therapy or mechanical ventilation). This group of COPD patients with advanced disease might be at risk of increased comorbidities and mortality as recently shown in a large Veterans Administration trial. ${ }^{6}$ COMET will allow us to assess the safety profile of a self-management program in patients with advanced COPD. In addition, the study will provide data to describe the relationships between oxygen therapy compliance, hospitalization, exacerbations, and other COPD-related outcomes.

Another important novelty of the study includes combining a self-management program, an e-health platform, and home oxygen monitoring. A distinction from some previous COPD self-management programs is that all decisions regarding medication are made by a physician to avoid inappropriate medication. Another methodological aspect of the study is the attention given to implementing quality assurance with respect to the regular training of the health care professional CMs, standardization of the educational program, and support by the CMs during the study. Furthermore, this study does not limit assessment to only trial outcome measures such as patient health and hospitalizations, but also includes process measures (eg, patient acquisition of skills and behavioral changes). The intent is to gather information that could facilitate the interpretation of trial outcomes. Finally, this trial insures validation of the primary outcome by including an Endpoint Validation Committee to assess the reasons for acute care hospital admissions and prolonged stays.

\section{Conclusion}

This trial has the potential to promote changes in improving home-based COPD management and patient health. Furthermore, if the program reduces health care expenses as expected, its cost-effectiveness across different settings should provide an additional incentive to expand the program internationally.

\section{Acknowledgments}

The authors sincerely thank all the COMET personnel who participated in this study, in particular the VitalAire case managers from the four countries, the three members of the Endpoint Validation Committee (Dr Bucknall, Respiratory Medicine, Glasgow Royal Infirmary, Scotland, United Kingdom; Prof Burgel, Pneumologie et Centre de Mucoviscidose de l'adulte, Hôpital Cochin, Paris, France; Prof Vogelmeier, Pulmonary Division, Marburg University Hospital, Germany), and the COMET investigators: Dr Aguar 
Benito, Medicina Interna, Hospital Arnau de Vilanova, Valencia, Spain; Dr Ancochea Bermudez, Neumología, Hospital La Princesa, Madrid, Spain; Dr Arnal, Réanimation, Hôpital Sainte Musse, Toulon, France; Dr Bastian, Pneumologie und Beatmungsmedizin, Marienkrankenhaus Kassel, Germany; Prof Bergeron, Pneumologie, Hôpital Saint-Louis, Paris, France; Dr Botrus, Pneumologie, Centre Hospitalier Régional Metz Thionville, France; Prof Charpin, Pneumologie - Allergologie, Hôpital Nord, Assistance Publique, Hôpitaux de Marseille, France; Dr Chavaillon, Pneumologie, Centre Hospitalier d'Antibes-Juan-les-pins, France; Prof Cornelissen, Pneumologie, Universitätsklinik, Aachen, Germany; Dr De Abajo, Pneumología, Hospital Universitario De Burgos, Spain; Prof Devouassoux, Pneumologie, Hôpital de la Croix Rousse, Lyon, France; Dr Díaz Lobato, Neumología, Hospital Universitario Ramón y Cajal, Madrid, Spain; Dr Goupil, Pneumologie, Centre Hospitalier, Le Mans, France; Prof Herth, Pneumologie und Beatmungsmedizin, Thoraxklinik Heidelberg, Germany; Dr Kropf, Pneumologie, Universitätsklinikum Ulm, Germany; Dr Nilius, Klinik für Pneumologie, Helios Klinik Hagen - Ambrock, Hagen, Germany; Prof Pepin, Rééducation Physiologie, CHU de Grenoble, France; Dr Pietra, Pneumologia, Ospedale San Carlo Borromeo, Milano, Italy; Dr Rampoldi, Riabilitazione Pneumologica, Azienda Ospedaliera di Desio e Vimercate, Seregno, Italy; Prof Randerath, Pneumologie und Allergologie, Krankenhaus Bethanien, Solingen, Germany; Dr Reißig, Pneumologie, Fachkrankenhaus Kloster Grafschaft, Schmallenberg, Germany; Dr Riesco, Neumologia, Hospital San Pedro de Alcantara, Caceres, Spain; Dr Rodriguez Gonzalez-Moro, Neumologia, Hospital Gregorio Marañón, Madrid, Spain; Dr Rolo, Pneumology, Villa Marelli, Milano, Italy; Dr Salmeron, Pneumologie Allergologie/Tabacologie, Groupe Hospitalier Saint Joseph, Paris, France; Dr Scavalli, Fisiopatologia Respiratoria e Allergologia, Ospedale Andosilla di Civita Castellana, Italy; Prof Similowski, Pneumologie et Réanimation, Groupe hospitalier Pitié-Salpétrière, Paris, France; Dr Tubaldi
Alberto, Pulmonary Diseases, Ospedale di Macerata, Italy; Dr Voicu, Pneumologie, CHR Metz-Thionville - Hôpital de Mercy, Metz, France; Dr Westhoff, Innere Medizin, Pneumologie, Lungenklinik Hemer, Germany.

Medical writing assistance in the preparation of this manuscript was provided by Kurt Liittschwager of 4Clinics (Paris, France). Funding support was provided by Air Liquide Healthcare.

\section{Author contributions}

Study concept and design: Jean Bourbeau, Joëlle Texereau, Romain Kessler. Drafting of the manuscript: Jean Bourbeau, Silvia Tognella, Peter Haidl, Joëlle Texereau. Critical revision of the manuscript for intellectual content: Pere Casan and Romain Kessler. All authors contributed toward data analysis, drafting and critically revising the paper and agree to be accountable for all aspects of the work.

\section{Disclosure}

Joëlle Texereau is an employee of Air Liquide Healthcare, Medical R\&D. The other authors report no conflicts of interest in this work.

\section{References}

1. Hilleman DE, Dewan N, Malesker M, Friedman M. Pharmacoeconomic evaluation of COPD. Chest. 2000;118(5):1278-1285.

2. Bourbeau J, Lavoie KL, Sedeno M. Comprehensive self-management strategies. Semin Respir Crit Care Med. 2015;36(4):630-638.

3. Adams SG, Smith PK, Allan PF, Anzueto A, Pugh JA, Cornell JE. Systematic review of the chronic care model in chronic obstructive pulmonary disease prevention and management. Arch Intern Med. 2007; 167(6):551-561.

4. Katsenos S, Constantopoulos SH. Long-term oxygen therapy in COPD: factors affecting and ways of improving patient compliance. Pulm Med. 2011;2011:325362.

5. Bourbeau J, Julien M, Maltais F, et al. Reduction of hospital utilization in patients with chronic obstructive pulmonary disease: a disease-specific self-management intervention. Arch Intern Med. 2003; 163(5):585-591.

6. Fan VS, Gaziano JM, Lew R, et al. A comprehensive care management program to prevent chronic obstructive pulmonary disease hospitalizations: a randomized, controlled trial. Ann Intern Med. 2012; 156(10):673-683.
International Journal of COPD

\section{Publish your work in this journal}

The International Journal of COPD is an international, peer-reviewed journal of therapeutics and pharmacology focusing on concise rapid reporting of clinical studies and reviews in COPD. Special focus is given to the pathophysiological processes underlying the disease, intervention programs, patient focused education, and self management protocols.

\section{Dovepress}

This journal is indexed on PubMed Central, MedLine and CAS. The manuscript management system is completely online and includes a very quick and fair peer-review system, which is all easy to use. Visit $\mathrm{http}: / / \mathrm{www}$.dovepress.com/testimonials.php to read real quotes from published authors. 